\title{
Model for Quality Evaluation and Improvement of Distance Higher Education based on Information Technology
}

\author{
Gina Mejía-Madrid \\ Universidad Central del Ecuador \\ Quito \\ Ecuador \\ gsmejia@uce.edu.ec
}

\author{
Rafael Molina-Carmona \\ Universidad de Alicante \\ Alicante \\ España \\ rmolina@dccia.ua.es
}

\begin{abstract}
The article describes a proposed model for assessing the quality of higher distance education based on the technologies of the Information and Communication. This model can be adopted by higher education institutions in order to ensure proper use of Information Technologies and Communication in teaching and learning processes, and academic processes and / or administrative processes. This research will use models and success stories from other countries as a basis for generating a preliminary model. Furthermore, this research contains initial reports and results as to justify the contribution of it.
\end{abstract}

\section{CCS Concepts}

- Apply computing $\rightarrow$ Education $\rightarrow$ Distance Learning - Apply computing $\rightarrow$ Education $\rightarrow$ Learning management system $\bullet$ Apply computing $\rightarrow$ Education $\rightarrow$ E-learning - Apply computing $\rightarrow$ Education $\rightarrow$ Collaborative learning

\section{Keywords}

Learning and Knowledge Technology, Distance Learning Evaluation, Model for Quality Evaluation in Distance, Online and /or Education, Improved teaching and learning processes with information technology and communications

\section{INTRODUCTION}

Being a teacher is one of the most wonderful experiences in the life of a person. I believe that everyone can teach others not only in academic tasks but also in the experiences of life; and even more in this last decade of the century when the information society and knowledge economy are booming.

In addition, the modeling of processes of teaching and learning using technology Information and Communication Technologies (ICT) or also called Learning and Knowledge Technologies (LKT) are breaking paradigms to improve learning centered on the students who will be the future professionals.

On the one hand, it is essential to contribute to a model of evaluation and improvement of distance education that primarily benefits the students who live in rural areas and cannot attend universities for quality education. On the other hand, teachers who can apply teaching methodologies appropriate for students to learn and manage their own knowledge.

In addition, society demands creative individuals, entrepreneurs, competent in handling technology, independent and prepared to function in their social environment. This is leading to a profound change in teaching methodologies in general and, particularly in distance education because of the need for a more autonomous learning and the availability of more sophisticated technologies.

Modern educational theories attempt to answer these needs giving the student a more active role. The paradigm of student-centered learning allows customization of the learning experience and adaptation to diversity, so that it can adapt to different learning styles and different types of intelligence. To develop learning centered on the student an excellent strategic ally may be the technologies of information and communication that allow mass access and distance education, as well as personalization, allowing to give solutions to the heterogeneity of students, promoting progressive, autonomous and adaptive learning and finally the motivation.

There has been a very active research in this area, but somehow the experiences are still quite specific and isolated. In conclusion, from our point of view there are three key elements in the success of distance education proposal:

1. The adequacy of the learning process, to foster motivation and adaptation to the rhythm of student learning and adapted to distance learning. The teaching methodology is the main variable to consider.

2. The adequacy of the technological resources that support the teaching and learning processes. In particular, variables such as availability of access technologies (mainly Internet) or learning technologies are considered.

3. The adequacy of administrative processes, in the broadest sense, including variables such as regulations, laws and rules or resource availabilities.

Based on this background, the doctoral thesis project seeks to define a model to assess the quality of distance education plans and propose the necessary measures to achieve the objectives of adequacy of these three fundamental elements. In addition, it will be applied as a case study at a public university of Ecuador, which will allow us to validate the proposed model.

\section{STATE-OF-THE-ART}

Higher education is driven by globalization and the knowledgebased economy. It is estimated that the demand for higher education by 2030 will be about 400 million people This demand 
would need to create 2 universities for 20,000 students each day for the next 20 years. Is it possible to create this large number of traditional universities? Is it sustainable? [1]. Educate by traditional forms and satisfy all the demand of the population is practically impossible. Distance education is over a hundred years old and according to Garrison [2] is divided into three generations of technological innovation that he identifies as correspondence, telecommunication and telematics. This latest generation of telematics starts from the decade of the 80 with the computer assisted instruction and student-centered.

Other authors classify the first generation from 1850 to 1960 predominating the printers, radio and television. The second generation (1960 - 1985), occupied multiple technologies without computers, for example, audiocassettes, television, videocassettes, fax and printers. The third generation (1985-1995) included computers and networks. In the fourth generation was incorporating computers with broadband technologies, video conferencing, real-time software with audio and video. Each new generation increases opportunities to improve communication and collaboration from student to student and teacher [3].

Additionally, there is a new generation with the advent of the internet, technological developments, web 2.0 and availability of digital content. In the last generation, it is important to mention that the information and communications technology play an indispensable role as they improve teaching and learning processes with the implementation of personal learning environments, synchronous and asynchronous communication between students and teachers, use of virtual libraries and variety of educational resources in all forms.

These emerging technologies have come to change society in the era of information and knowledge. In this society, culture and human behavior have changed radically. This has impacted the ways of teaching and learning. Subsequently, in recent years we live in the digital society by our dependence on everything digital, here learning is a shared task. This leads to new forms of education, methodologies to learn how elerning, b-learning, colaboration, mobile and unseen-liquid [4].

With this background, the University is the center of research and innovation in the knowledge society and, in the not too distant future, all universities will develop some form of distance education. It is also important to emphasize that this distance education should be of high quality and must ensure the training of highly qualified professionals.

Moreover, the report issued by Unesco in the 60th anniversary year 2006 says: The open and distance learning is one of the areas of education which are developing faster. Governments around the world are increasingly promoting the use of open and distance learning as a complement to traditional educational structures. [5].

In Paris in 2009 at the World Conference on Higher Education it was established that the open distance learning and use of ICT offer opportunities to expand access to quality education, i.e., particularly when open educational resources are easily shared between several countries and higher education institutions.[6]

The conceptual and epistemological distance education are welcomed in the studies and documents of the UNESCO of Distance Education, International Council for Open Distance Education (ICDE) [7], the American Association of Higher Distance Education [8] the Inter-American Distance Education Consortium (CREAD), and Virtual Educa Project, attached to the Summit of Heads of State Ibero-American.

As the study of art established the rise of distance education observed for this reason it is necessary to propose models to ensure quality. Although the culture of quality is already very introduced in the universities there are not many studies on the quality assurance of distance education. It is important to note that distance education has special features one of which is the implementation of information technology and communication in the teaching and learning processes. Moreover, this has the peculiarity that there is no physical presence of students in the physical infrastructure of the university and the key element is to present the same opportunities as if they were student modality within the University [9].

To ensure the quality of distance education is necessary to study different aspects. One of the them, is the quality assurance of technology for learning and knowledge [10]. Today, it is fundamental in education but more essential in distance education or online. This helps us improve the teaching student-centered learning with the implementation of virtual methods, with this contributing to achieve the objectives or learning outcomes established in curriculum planning.

There are many previous experiences on quality in university studies and particularly in distance education [11]. For example, the generic assessment model learning environment face and blended races of universities and polytechnics of Ecuador[12]. This model indicates a particular vision of higher education in Ecuador, including some specific elements on blended learning. It is a very particular model, focused on the measurement of a set of indicators and the definition of metrics to evaluate the quality.

Another example is the model containing the standards and guidelines for quality assurance in the European Higher Education Area [13]. It is a generic model that provides a broad and comprehensive view of quality in higher education. In none of the cases specifically dealing with the learning and knowledge technologies in distance education.

\section{HYPOTHESIS AND RESEARCH QUESTIONS}

In this section we propose a hypothesis of the research:

It is possible to establish a proposal for a model to evaluate distance education through information technologies that verifies the quality of a course, career or academic program at a university from Ecuador and then propose an improvement plan.

The hypothesis is going to be tested by these research questions. These questions are described below:

1. What is quality in the context of higher education? What parameters are used to measure it?

2. What are the regulations, laws and rules affecting distance education?

3. What teaching and learning resources are needed to provide quality distance education?

4. What teaching methods are more efficient for distance learning to encourage motivation and adaptation to the rhythm of student learning?

5. What technologies allow students access to distance education with quality guarantees?

6. What learning technologies are most effective for distance learning quality?

7. What indicators can be defined to measure each of the variables in distance education? 
8. How you can structure a model for assessing the quality of a distance teaching program that uses information and communication technologies?

9. What improvement actions can be applied to a teaching program that has been evaluated?

10. What would be a model action plan or improvements to implement the model in an academic program or online course at a University of Ecuador?

\section{RESEARCH OBJECTIVES}

After having stated the research hypothesis to be proven, the main objective of this work can be established as follows:

Design a proposal of a model of evaluation for higher distance education (online or virtual learning) through the use of information and communication technologies. This model should verify the quality of an online course, academic program or career; and propose improvements necessary to meet established objectives. In addition, this proposed model could be verified in two case studies at the Central University of Ecuador and the University of Alicante.

To achieve this objective, we set the following specific objectives:

1. Define the concept of quality in the context of higher education in particular distance, online or virtual modalities.

2. Determine the legal and technical instruments of entities that regulate and control the system of higher education in the country. Similarly, investigate other rules and regulations at both national and international level.

3. Define the teaching-learning resources, and more effective teaching methods for distance learning technologies. Furthermore, defining variables associated with each of these elements.

4. Identify the indicators needed to measure each of the variables defined.

5. Determine the improvement actions that can be applied to a teaching program based on the measured indicators and the program objectives.

6. To design a proposal for a model to evaluate and improve the quality of distance education integrating the defined indicators and the identified improvement strategies.

7. Establish a plan of action to implement the evaluation model at the Central University of Ecuador and the University of Alicante. Validate the model by applying these two cases. Make adjustments to the model.

8. Extract conclusions from the model and its application.

\section{RESEARCH APPROACH METHODOLOGY.}

AND

The methodology that we use is basically Action Research, which can be summarized in the following steps:
1.- The problem to solve is chosen.

2.- The relevant literature is reviewed.

3.- It poses questions to answer.

4.- It poses tentative answers.

5.- The methodology to collect data is determined.

6.- Data is collected.

7.- The information is analyzed.

8.- The conclusions are shared.

Action research does not have an end point so this is always new questions. This methodology is summarized in: plan, implement, evaluate and reflect, as shown in Figure 1 [14].

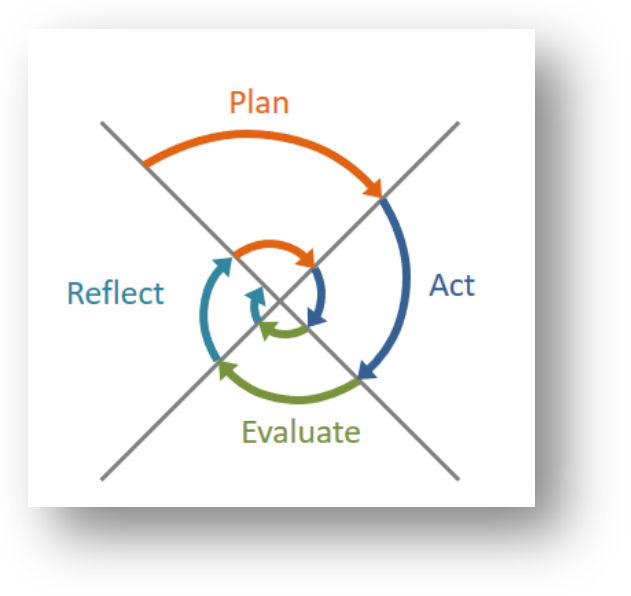

Figure 1. Action Research Method

Using this methodology, research was carried out in three phases:

- Document search, to collect and analyze the state of the art and existing previous results. Through the document review the analysis and systematization of useful information, preferably using inductive and deductive methods will be developed. In addition, theoretical research and state of the art: methodological framework, E-learning, assessment processes, teaching and learning processes, Inter-Learning, Quality Assurance Accreditation of Higher Education, Quality Management Systems. In addition, this document search allows the collection of information both to lift the diagnosis of the course or distance learning program, and the development of the proposed methodological framework and action plan. Field Research through interviews and surveys to supplement the document review. Furthermore, the field allows observation in direct contact with the object of study.

- Proposed model. In this stage a new original model is designed. This model will be based on documentary search (state of the art) and the respective analyzes.

- Implementation and validation, in which the model will be implemented. Data will be collected. The model will be analyzed and validated. This will detect shortcomings and possible improvements to be addressed in the next cycle of action research methodology. 
Moreover, this research is qualitative and quantitative, since the description, interpretation, situational analysis of the case study will be used for the proposal of a model to evaluate the quality of distance education in public universities in Ecuador. Furthermore, both positive and negative aspects of models of evaluation, methodological tools, learning models, previous research and best practices on model for evaluating the quality of higher education using information and communication technologies will be discussed. On one hand, research generated by educational innovation conferences will be reviewed; on the other hand, the model will be verified using the case of a public university of Ecuador.

The generic model by the Council of Evaluation, Accreditation and Quality Assurance of Ecuador will be used to assess learning environments. To implement this model, a collection of evidence for each of the indicators is performed, as well as bibliographic collections, through texts and / or articles describing the operation and processes of each of the indicators of this model. Then the base line of research is determined.

Subsequently, a critical analysis of the indicators and / or positive and negative elements of national and international standards, reference works, previous research and best practices will be made. Next, this analysis, a model will be designed to evaluate the quality of distance education in a career or course using information technology and communication for public universities in Ecuador. Then, the situational diagnosis based on the information gathered, the evaluation model will be completed and the feasibility of its application will be discussed in a course or program.

Finally, a maturity model will be proposed, to allows locating the level of quality of distance higher education.[15]

\section{RESULTS TO DATE}

So far, the results of this research are:

It is noteworthy that after establishing the state of the art which investigated cases of success, models and documentation relating to the quality of the education at distance, online and virtual, firstly, we studied and collected information on indicators that may be applicable to the distance education using the generic model to evaluate learning developed by the CEAACES [12]. Secondly, we have studied the model containing the standards and guidelines for quality assurance in the European Higher Education Area [11][16]. Thirdly, we have proposed a preliminary model, a prospective basis, which includes the main elements from our point of view should be considered when evaluating the quality of distance education, online or virtual.

The following sections describe the progress made in each of these aspects.

\subsection{Baseline using the CEAACES model}

The Theory of Multiple Criteria (TDM) decision is the fundamental basis of the generic model for the assessment issued by the CEAACES. Moreover, this theory is the methodological basis for solving problems in complex systems. This model consists of five criteria: Relevance, Curricular plan, Academy, Institutional environment and Students. It has 36 indicators: 24 quantitative and 12 qualitative. Each indicator has an explicit formula (evidence) or an assessment of its elements[12]. The criteria are:

A.- Relevance: This criterion evaluates whether the career or academic program meets the expectations and needs of society, national planning, the prospect of global scientific, humanistic and technological development and cultural diversity, as support for developing the professional profile. [12]

B.- Curricular plan: This criterion evaluates the different levels of specification of the curriculum ensuring coherence and integration between the macro, meso and micro curriculum [17].

C.- Academy: This criterion evaluates teachers of the academic program. Teachers are the staff who is directly responsible of the teaching-learning process, research and relationship with society, who must have the necessary skills.

D.- Institutional environment: This criterion assesses the academic management system of the academic program, executed by a coordination management / processes responsible for monitoring and academic curriculum support resources related to the library and laboratories. All this to ensure compliance with the own goals and improving the quality of education [17].

E.- Students: This criterion evaluates student participation in complementary activities, tutoring, student welfare policies and the process of accreditation of courses

With this background, a preliminary baseline using the Generic Model for assessing learning environments was generated. It is also analyzed how this model can be adapted to the academic program of a distance course in public universities of Ecuador.

On the one hand, this instrument allowed us to define the current preliminary state of the quality of distance education in the Central University of Ecuador - UCE-. This was the program of Commercial Engineering. On the other hand, it is important to mention that a preliminary review of the use of Information Technology and Communication in the teaching and learning processes was made to detect if it is important to change elearnig technology platform.

With this information a preliminary study about the distance academic program was made at the UCE. Figure 2 contains data about the preliminary results of the criteria of Relevance, Curriculum, Schools, Institutional Environment and Students which were explained above. The results of the blue column are the maximum values for each criteria and the red columns are the preliminary results for each of the criteria. 


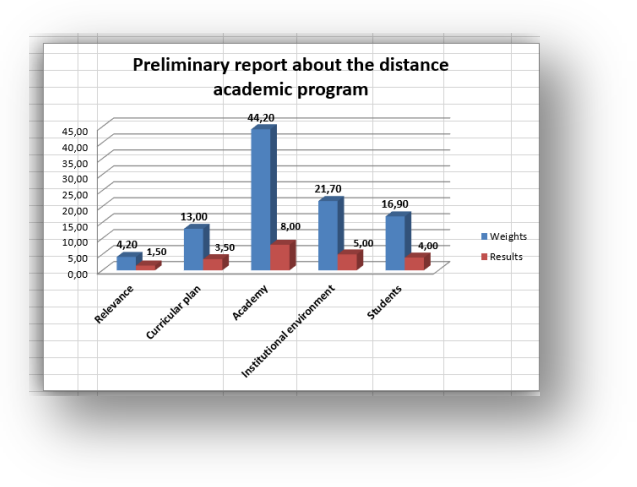

Figure 2. Preliminary results of the distance academic program at the UCE

Subsequently, this baseline (which is one of the main contribution of this paper) and various research on the subject and the state of the art worldwide, we present a proposed model of quality assessment of distance education. This proposal of a model must be progressive and measure the quality of teaching and learning processes and the learner-centered methodologies proposed by teachers. Finally, what we seek with this research is to achieve academic excellence in teaching and learning processes incorporating ICT and LKT.

In conclusion, we have studied the model CEAACES and obtained preliminary results. This model is very concrete and proposes many indicators but does not include all the aspects necessary to assess the quality of distance education. In addition, this model can not be applied in full to a distance program or virtual course as it is not based information technology. IT is the means of communication between teachers and students in the process of teaching and learning and the means to develop teaching materials.

Furthermore, it was not possible to have all the information of the academic program because it was not available for different reasons. It is noteworthy that the studied distance academic program not yet has all the multimedia and digital educational resources that can support the work of teaching and learning processes of teachers and students.

\subsection{Preliminary adaptation of the European Higher Education Area model (ESG)}

We have studied the model containing the standards and guidelines for quality assurance in the European Higher Education Area [13] [16]. This is a model that provides a broad and comprehensive view of quality in higher education. We have answered questions like:

1. What can we learn from this model with regard to Learning and Knowledge Technology (LKT)?

2. How can we realize the guidelines of the European model in the form of indicators and metrics to evaluate?

We have obtained the first conclusions adapting each of the ten criteria provided by the European model. In addition, we have obtained a set of guidelines on quality assurance of the LKT in teaching and learning processes. These results are shown below:

1. The LKT should be incorporated into the cycle of continuous improvement and institutional quality culture.
2. The LKT must be formally associated with policies related to teaching and learning.

3. The LKT are part of the strategic approach of the institution.

4. The LKT should allow tutored personalized assistance

5. The LKT must be in the processes for program design.

6. The LKT should support the objectives of the academic programs to be met.

7. The LKT should support the achievement of the expected learning outcomes.

8. The LKT should support the acquisition of academic knowledge as well as skills that help the personal and professional development into the future.

9. The LKT should help the student participation in the development of academic programs.

10. The LKT should stimulate motivation, self-reflection and student participation in the learning process.

11. The LKT should focus on student-centered learning.

12. The LKT should allow flexible learning depending on the needs of students.

13. The LKT should include different modes of delivery of teaching and learning processes.

14. The LKT should help the implementation of various educational models.

15. The LKT should encourage learner autonomy, ensure the support and alignment with the teacher.

16. The LKT will help the student assessment so that they can measure progress in the learning process and to what extent the learning outcomes are achieved.

17. The LKT will assist the implementation of consistent and transparent policies for admission, recognition and completion of students.

18. The LKT help establish processes and tools to collect data and track the progress of students.

19. The LKT will help identify prior learning and learning outcomes that are achieved.

20. Teachers must develop skills in the use of the LKT.

21. Instruction courses must be developing so that teachers cand apply the LKT in the subjects.

22. The LKT should be included in each of the subjects by the teacher.

23. The LKT should encourage innovation in teaching methods and the use of new technologies.

24. The LKT should be included in the teaching and learning processes.

25. The LKT should provide sufficient learning to students and easily accessible resources.

26. The LKT will help the different modes of teaching and learning flexible depending on the needs of students.

27. The LKT help for students are kept informed of the available services

28. The LKT should be part of all academic resources that will be offered

29. The LKT should support students and learning available resources.

30. The LKT should help measure student progress, success rates and abandonment.

31. The LKT will help implement mechanisms for disseminating public information.

32. The LKT will be used in the methods of teaching, learning.

33. The LKT will assist the monitoring, evaluation and periodic review of the curriculum.

34. The LKT will help promote research in the relevant discipline, ensuring that the program is updated. 
35. The LKT should facilitate the interaction between teacher and student

36. The LKT should be included in the curriculum proposals

37. The LKT should allow for diversity and accessibility to learning resources.

38. The LKT should be included in the external evaluation [13].

\subsection{Proposed model for evaluation and quality improvement in distance education}

The main contribution we have made is a first proposal of the elements of a model for evaluation and quality improvement in distance education. These elements are: learning and knowledge technology, teaching and learning processes enhanced with ICT and strategic processes that support the distance education. This proposed model can be seen in Figure 3 below.

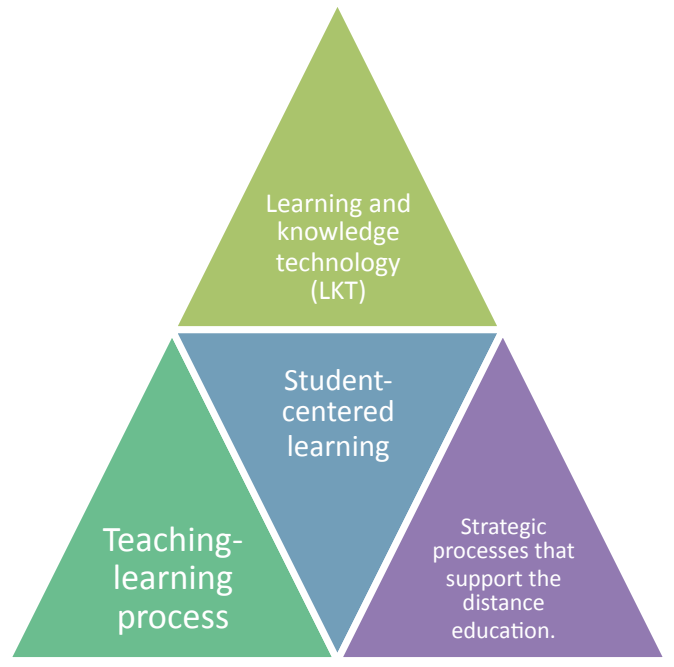

Figure 3. Proposed model for quality assessment of distance education.

\section{DISSERTATION STATUS}

This research is in the first iteration of the process of action research. In this first iteration, the state of each of the phases is:

In the phase of search and document analysis, we have made a state of art, focusing on the Ecuadorian and European models, detecting its shortcomings regarding the implementation of learning and knowledge technologies. At this stage we have found some documentation on methodologies and literature on elearning, distance education, models of quality assessment of distance, online or virtual learning.

In the proposal stage model it is defined the triangle of elements that should be studied to propose a model for quality assessment of distance learning. Right now, we are defining how to approach the study of these elements and has submitted a proposal with three elements: first, technology for learning and knowledge LKT; second, the teaching and learning processes enhanced with ICT; and thirth, strategic business processes that support the distance education.
The implementation and validation phase has not been implemented yet, but we intend to apply the triangular pattern on concrete cases of the Central University of Ecuador UCE and the University of Alicante, UA.

\section{CURRENT AND CONTRIBUTIONS} EXPECTED

In countries with developing educational structures, implementing distance education is crucial. In this context, the Learning and Knowledge Technologies (LKT) occupy a central role in the teaching-learning process to provide distance-learning students the same opportunities as attending students. To ensure this equality of opportunity is necessary to have a model to evaluate the quality of distance, online or virtual education.

Currently, we believe we have the following contributions:

First, the state of art has concluded that it is necessary and indispensable to define a model for evaluating and improving the quality of distance education since generic models are not enough. There are previous models, such as the ones of Ecuador and Europe, that serve as a starting point but they are not enough.

Second, it has been proposed a preliminary model that has 3 elements: the learning and knowledge technologies (LKT); the improved teaching and learning processes with ICT; and the strategic processes that support distance education. This contribution can be observed in Figure 3.

In this research, we will seek to contribute to the future following contributions:

- Application of the mathematical model of systems theory for the formulation of a model to evaluate the quality of distance education.[19] [20]

- Definition of a complex system [21] [22] of distance education [23].

- Definition of a model for assessing and improving the quality of distance education, that is complete and comprehensive in both width (take into account all aspects related to the quality of education) and depth (will consider every aspect in detail and providing metrics and indicators to measure quality and propose possible improvements).

- Development of tools for the collection, analysis and interpretation of data, necessary for the construction of the proposed model.

\section{REFERENCES}

[1] M. Aymerich, "Retos y tensiones de la virtualización de la Educación," pp. 2-3, 2015.

[2] R. Garrison and D. Keegan, "Características de la educación a distancia," 1987.

[3] M. S. McIsaac and C. N. Gunawardena, "History of Distance Education," España Rev. Iberoam. Educ. a Distancia RIED, vol. 6, no. 3, pp. 227-232, 2001.

[4] Garcia Aretio, "Contextos universitarios (Otra sociedad otras formas de aprender)," 2013. [Online]. Available: http://aretio.hypotheses.org/1265. 
[5] "observaciones rra de remad.pdf." .

[6] Unesco, "Conferencia Mundial sobre la Educación Superior - 2009," La nueva dinámica la Educ. Super. y la Investig. para el cambio Soc. y el Desarro., pp. 1-9, 2009.

[7] "International Council for open and distance education." [Online]. Available: http://www.icde.org/who-we-are.

[8] "USDLA, United States Distance Learning Associator." [Online].

Available: https://www.usdla.org/resources/errc/.

[9] P. Albert and S. Morer, "Los retos de la educación a distancia," vol. 2, no. 1981, 1995.

[10] D. Persico, S. Manca, and F. Pozzi, "Three by Three by Three: A Model for eLearning Evaluation," no. 1989, 2012.

[11] A. Journal and S. Publications, "A Technique for Quality Evaluation of E-Learning from Developers Perspective Majdi Abdellatief, Abu Bakar Md Sultan, Marzanah A . Jabar and Rusli Abdullah Department of Information System , Faculty of Computer Science and Information Technology ," vol. 3, no. 1, pp. 157-164, 2011.

[12] C. de Evaluación Acreditación de Carreras Programas, "Consejo de Evaluación, Acreditación y Aseguramiento de la Calidad de la Educación Superior MODELO PARA LA EVALUACIO N DE LAS CARRERAS PRESENCIALES Y SEMI-PRESENCIALES DE LAS UNIVERSIDADES Y ESCUELAS POLITE CNICAS DEL ECUADOR."

[13] Q. Assurance, H. Education, E. Students, and H. Education, "Criterios y directrices para el aseguramiento de Calidad en el Espacio Europeo de Educación Superior ( ESG )," 2015.
[14] E. Bausela, "La Docencia a Través De La InvestigaciónAcción,” Rev. Iberoam. Educ., pp. 1-10, 1984.

[15] R. Molina-carmona, P. Compañ-rosique, R. Satorrecuerda, C. Villagrá-, F. J. Gallego-durán, and F. Llorenslargo, "Technological Ecosystem Maps for IT Governance Application to a Higher Education."

[16] "Standards and Guidelines for Quality Assurance in the European Higher Education Area (ESG)," ENQA, ESU, EUA, EURASHE, Brussels, Belgium, 2015.

[17] C. De Evaluación and A. De Carreras, "Consejo de Evaluación, Acreditación y Aseguramiento de la Calidad de la Educación Superior,” 2015.

[18] I. G. M. Ecuador, "Reglamento de carreras a distancia, online y virtaul," no. 043, pp. 1-26, 1991.

[19] S. Melio, "INVITACION A LA TEORIA GENERAL DE SISTEMAS.pdf." .

[20] J. D. La Fuente, J. Santiago, A. Román, C. Dumitrache, D. Casasanto, and E. Morin, Enseñar a vivir, vol. 25, no. 9. 2015 .

[21] E. Morín, "RESEÑA LOS SIETE SABERES NECESARIOS PARA LA EDUCACIÓN DEL FUTURO Título: Los siete saberes necesarios para la educación del futuro," Ra Ximhai, vol. 1, no. 3, pp. 653$665,2005$.

[22] E. Morin and C.-J. Delgado-Diaz, "Reinventar la educación. Hacia una metamorfosis de la humanidad," pp. 1-18, 2014.

[23] B. Fainholc, "La calidad en la educación a distancia continúa siendo un tema muy complejo. Quality in Distance Education is Still a Very Complex Issue." 